\title{
El terratrèmol de l'11 de març del 2011 al Japó
}

\author{
Joan Aliberas \\ IES Josep Puig i Cadafalch, Mataró \\ María Luisa Arboleya \\ Departament de Geologia, Unitat de Geotectònica, Universitat Autònoma de Barcelona
}

El març passat un intens terratrèmol va sacsejar la costa oriental del Japó, produint un tsunami que va originar un nombre molt gran de víctimes i enormes danys materials. Vegem què va succeir.

Paraules clau: terratrèmol, Japó, magnitud, intensitat, tsunami

\section{Què va passar?}

Al meridià de Greenwich eren les 5 i 46 minuts de la matinada de l'11 de març passat quan la Terra començà a tremolar molt més fort de l'habitual en un punt situat a uns 129 km a l'est de Sendai, a Honshu, la gran illa central del Japó.

Quan encara no feia un minut que havien començat, les sacsejades ja arribaven a Fukushima, a 177 km de l'epicentre, i poc després a Tokio (fig 1), a 373 km i a tot el país en pocs minuts (fig. 2).

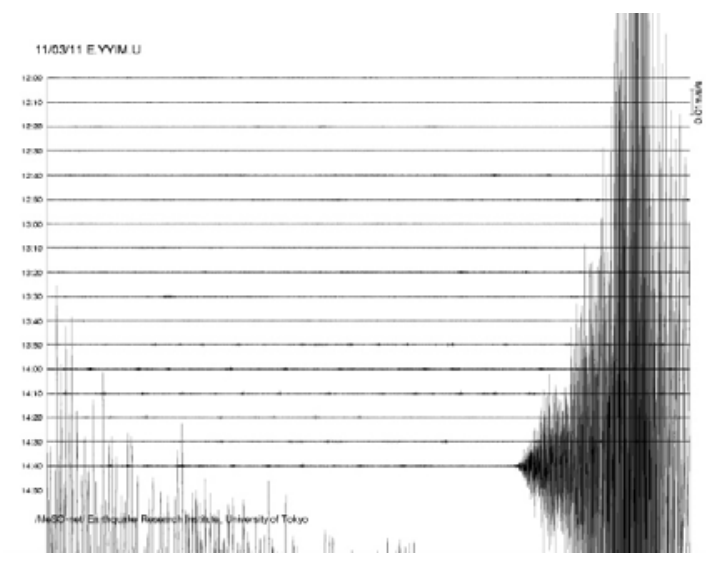

Figura 1. Enregistrament del sisme de Sohoku a la Universitat de Tokio. font
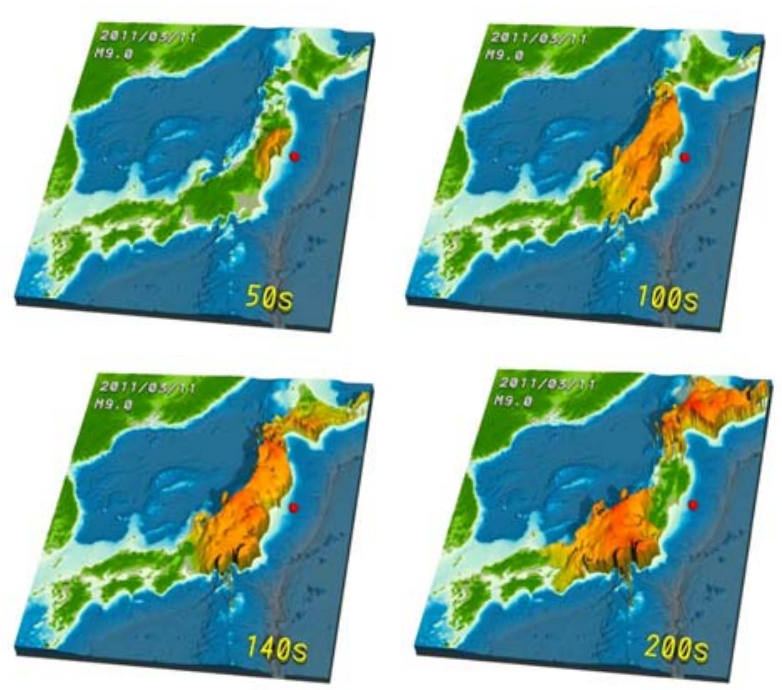

Figura 2. Propagació del sisme pel Japó. font

Les primeres mesures apuntaven a una magnitud de 8,9 però uns dies després es va considerar de $M$ 9,0. Es tractava d'un del terratrèmols més violents que s'hagin enregistrat mai fins ara (fig. 3). Però malgrat la violència, el terratrèmol va causar relativament pocs danys al Japó, un país preparat amb construccions antisísmiques. 


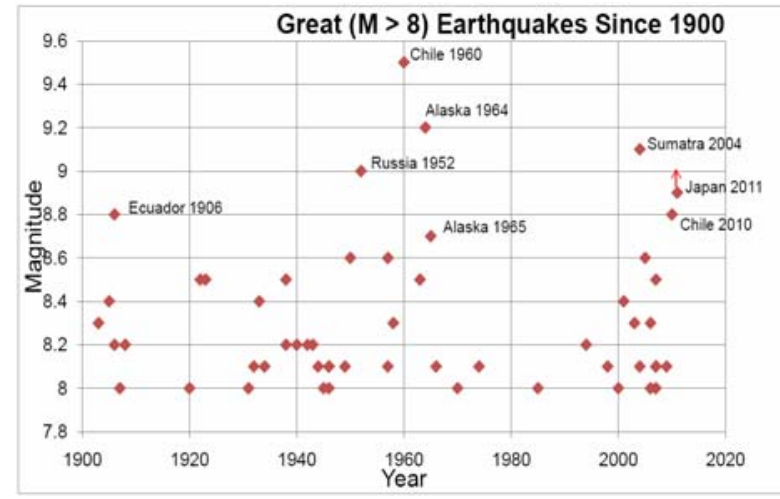

Figura 3. El terratrèmol de Sohoku és el quart més gran dels que s'han enregistrat a tot el món des de l'any 1900. font

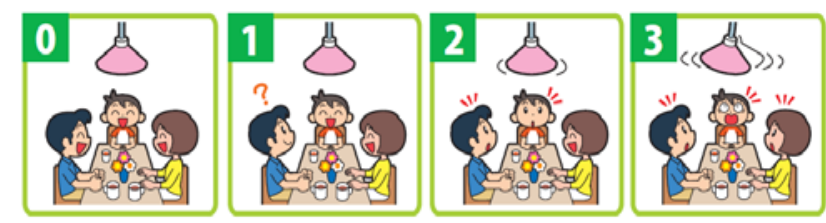

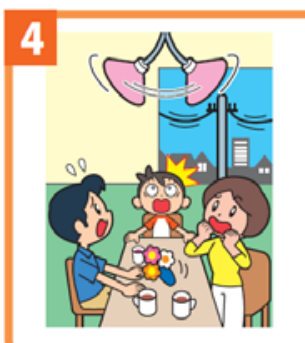
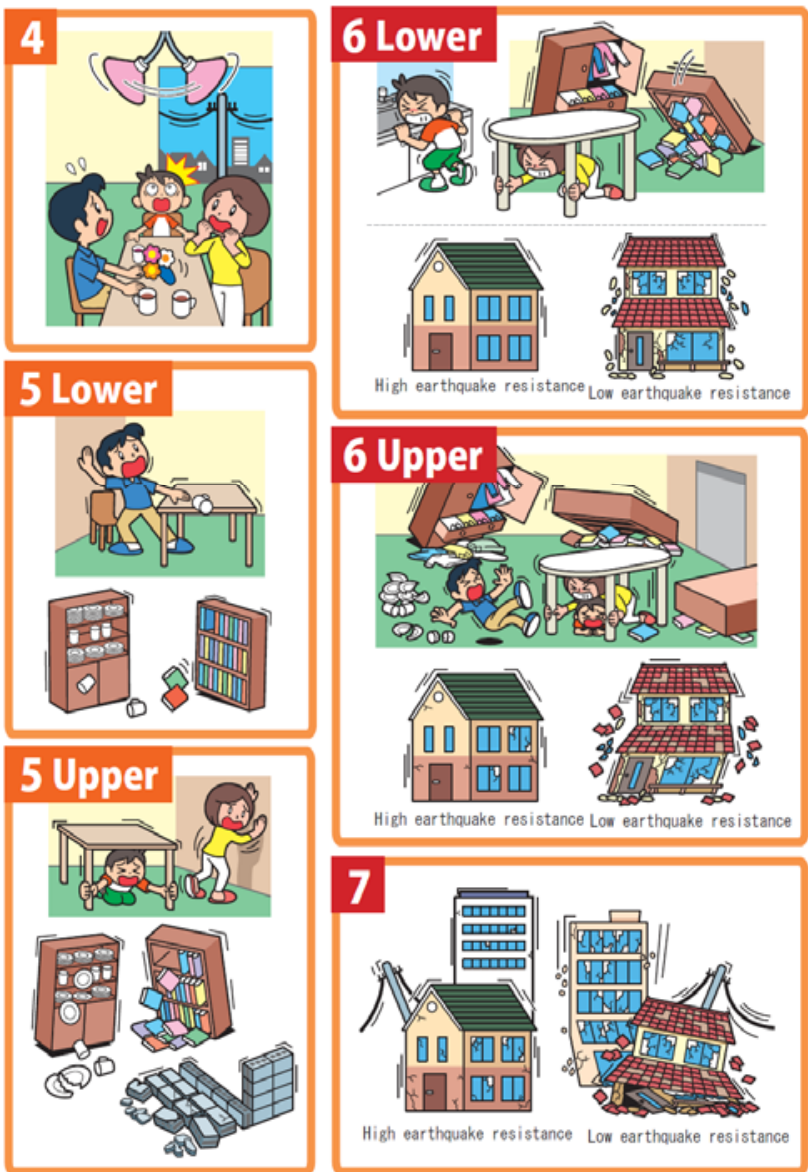

Figura 4. Cartell informatiu de l'agència meteorològica del Japó. S'hi mostren les diferències entre la construcció que està preparada per a sismes i la que no ho està. font
Podem fer-nos idea de fins a quin punt és fort comparant-ho amb el que es produí dos mesos després, l'11 de maig, a Llorca (Múrcia), causant greus destrosses amb una magnitud de tan sols 5,1 . Com que una diferència de 2 graus de magnitud indica mil vegades més energia, conclourem que el de Llorca va ser aproximadament un milió de vegades menys energètic. Encara que la distància $i$ la fondària no eren les mateixes, la diferència en els danys causats per les sacsejades només s'explica per la diferent preparació dels edificis davant del risc sísmic (fig. 4).

Els efectes del sisme es van mesurar amb instruments, obtenint resultats diferents al llarg del país, òbviament amb més intensitat -i capacitat destructora-com més a prop de l'epicentre (fig. 5).

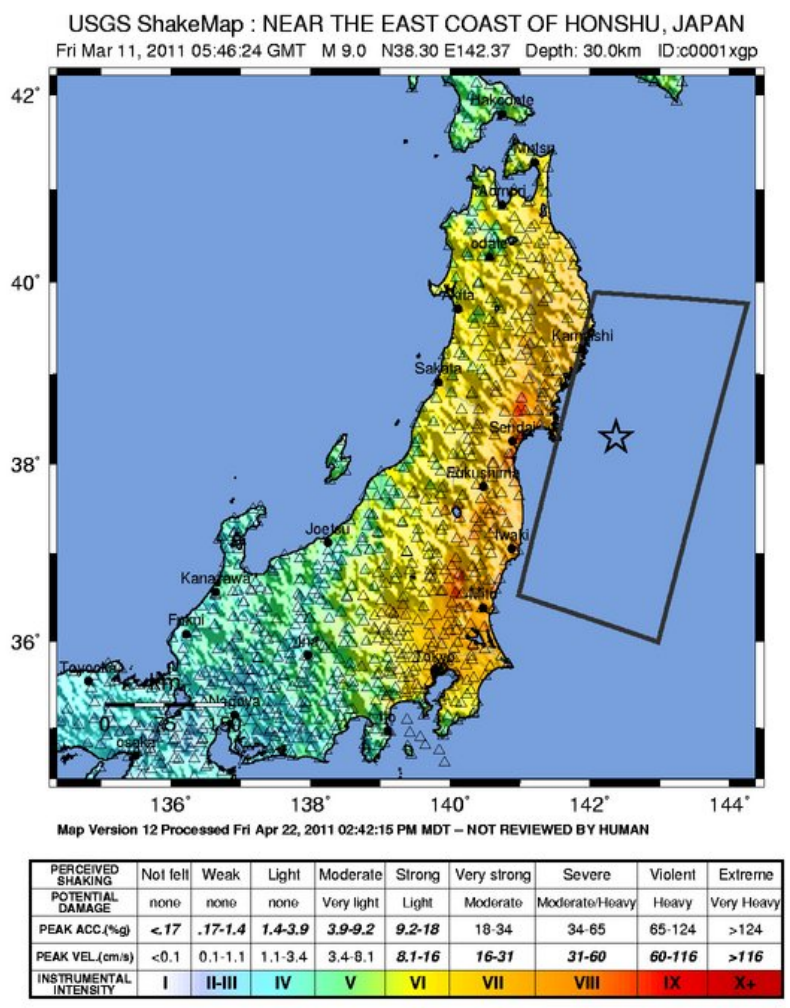

Figura 5. Mapa d'intensitat mesurada amb aparells. Com més vermell, més intensa la sacsejada. L'estrella assenyala l'epicentre i el quadrilàter la zona aproximada de la ruptura. font

\section{Per què va passar?}

Si el Japó és un país preparat com pocs per a grans sacsejades sísmiques no és per casualitat: l'arxipèlag japonès és un arc d'illes volcàniques format per la subducció de dues plaques tectòniques oceàniques (la del Pacífic i la de les Filipines) sota la placa d'Euràsia (figs. 6 i 7). 


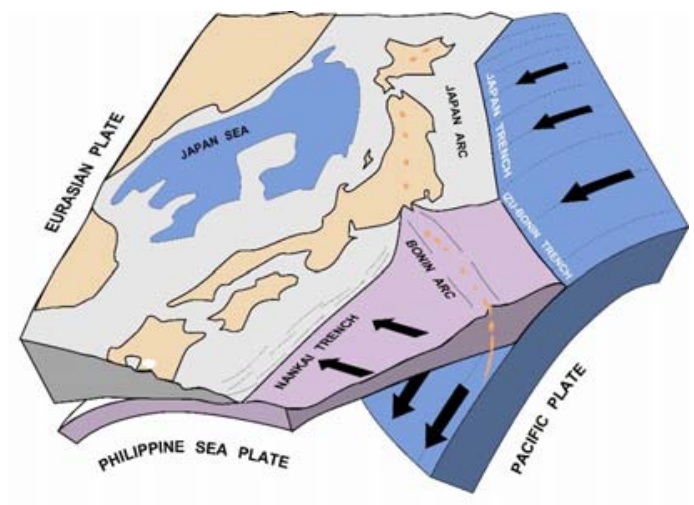

Figura 6. Diagrama mostrant el triple punt de coincidència de les plaques Euroasiàtica, de les Filipines i del Pacífic. font

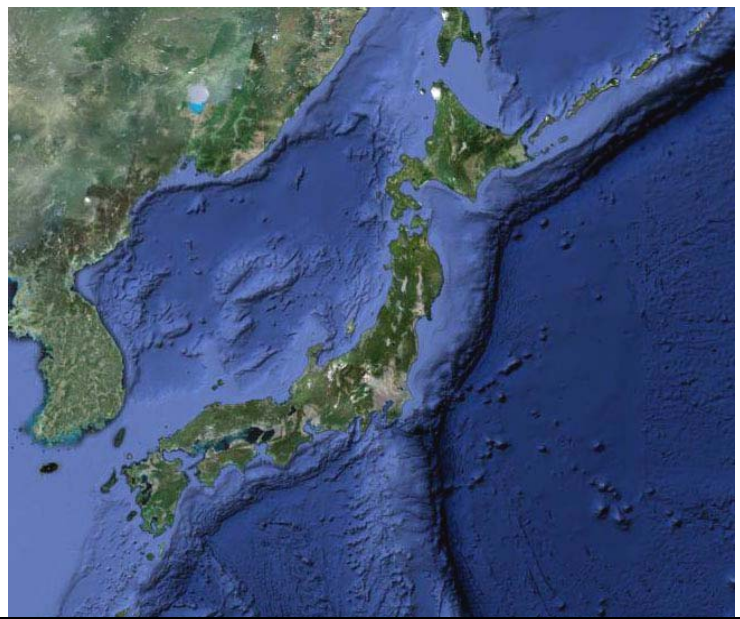

Figura 7. Imatge de Google Maps del Japó i del seu entorn submarí, mostrant les fosses que indiquen els límits de plaques en procés de subducció.

L'historial de terratrèmols a la zona ens en mostra una acumulació en una zona que comença a poca fondària i es va enfonsant a mida que va penetrant a sota de la placa on hi ha el Japó. El terratrèmol que ens ocupa, i el conjunt de les seves rèpliques, repeteix aquest mateix patró (figs. 8 i 9). Tot i que la majoria de terratrèmols es produeixen en els primers 200 km de fondària, se n'hi han detectat fins a prop dels $600 \mathrm{~km}$.

L'explicació és que la placa de l'oceà Pacífic es mou cap a l'oest empenyent contra l'euroasiàtica a una velocitat de 8,3 cm per any, una velocitat sorprenent tractant-se de plaques: a la de San Andrés, a Califòrnia, és de $4 \mathrm{~cm} /$ any. Això genera grans esforços entre les plaques, de manera que van acumulant energia fins que resulta bruscament alliberada durant els sismes.

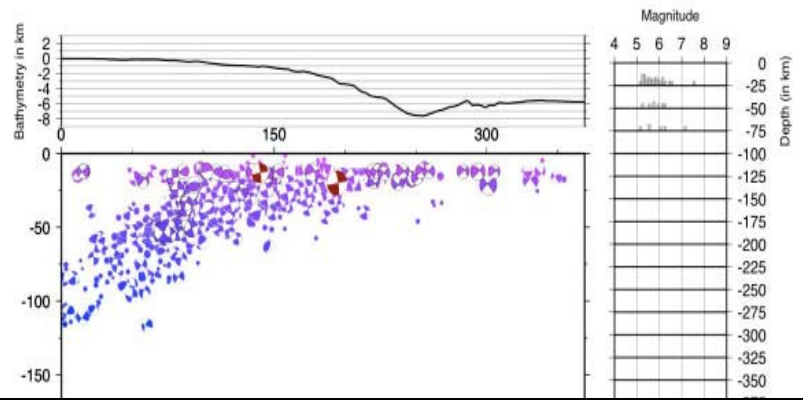

Figura 8. Secció transversal mostrant la sismicitat enregistrada a la zona posteriorment a l'11 de març del 2011. font

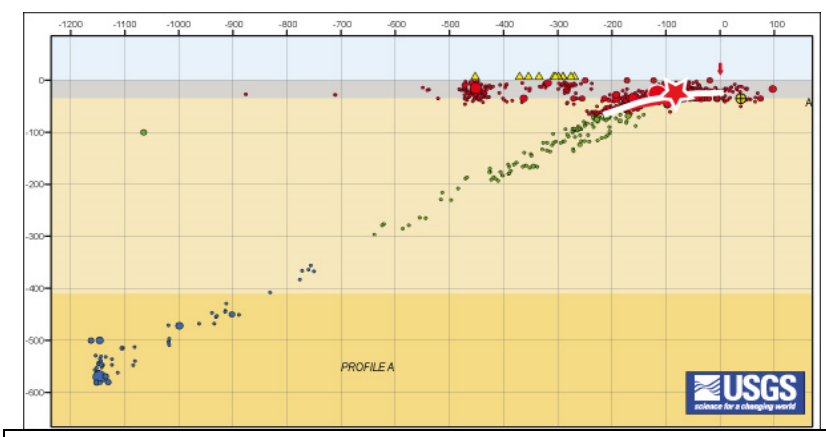

Figura 9. Secció transversal de la sismicitat al nord del Japó. L'àrea aproximada de la ruptura l'11 de març està indicada amb una línia blanca, i l'epicentre -el punt on va començar la ruptura- amb una estrella vermella. font

La dinàmica de les plaques causa l'acumulació d'esforços a les vores de placa. Quan els esforços acumulats són tan grans que superen el límit que les roques poden aguantar, es produeix una fractura acompanyada de lliscament entre les dues vores que s'han format i com a conseqüència d'aquest procés es produeix el terratrèmol. El moviment d'una zona de subducció es produeix al llarg de molt de temps (milions d'anys) i va acompanyat de trencament i lliscament sobre superfícies de fractura (megaencavalcaments) la formació de cadascuna de les quals provoca un terratrèmol. Per això es normal que una zona de subducció es trenqui moltes vegades al llarg de la seva història.

El terratrèmol de Sohoku va ser precedit per diversos terratrèmols més febles, quatre d'ells notables (entre els quals un de M7,2 i un altre de M6) i tot un seguit de rèpliques (una de les quals, de $M 7,1)$ durant els dies posteriors al terratrèmol principal, mentre el terreny anava assentant-se de nou (fig. 10). En tres dies i mig se'n comptaren més de quatre-centes i s'estima que se'n continuaran produint durant dos anys. 
GSem Earthquake sequence off coast of north eastern Honshu, Japan since $2011 / 03 / 09$

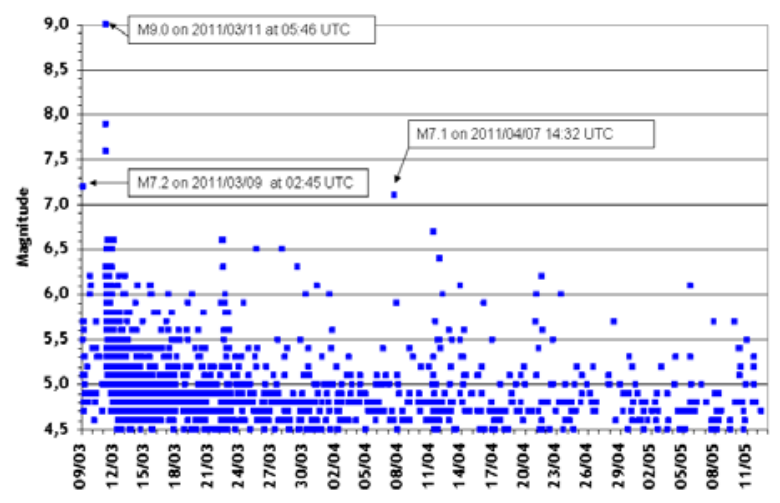

Figura 10. Seqüència de terratrèmols a la costa nord-est de Honshu entre el 9 de març i el 13 de maig. Al capdamunt, el sisme del dia 11 . font

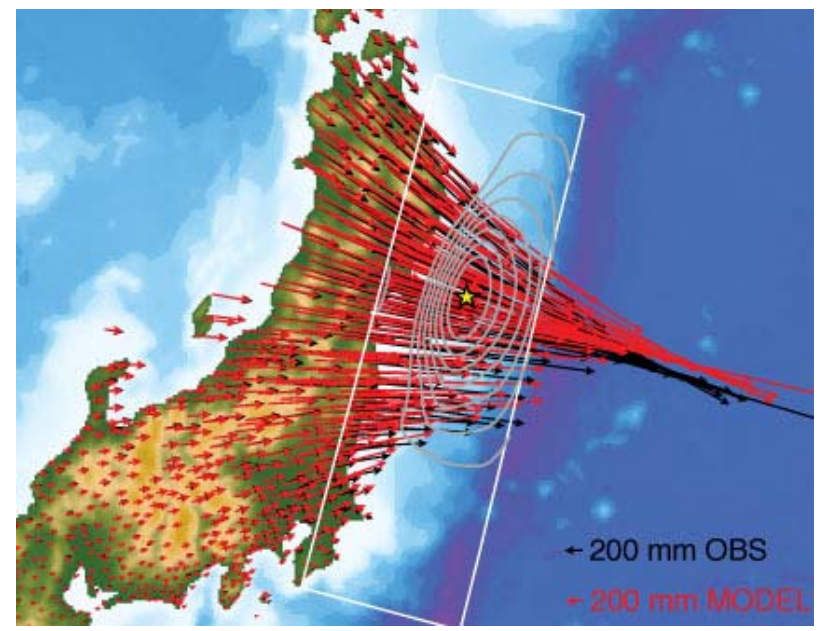

Figura 11. Moviments horitzontals mesurats amb GPS (negre) i predits pels models (vermell). font corresponent- va durar més de tres llarguíssims minuts. Feia 1200 anys que en aquella zona no es produiia un terratrèmol tan fort.

Utilitzant aparells GPS s'han pogut mesurar els desplaçaments produïts pel sisme: la costa oriental de l'illa va ser la que més es va desplaçar aproximadament cap a l'est (fins a uns $3 \mathrm{~m}$ ) (fig. 11) i la que més s'enfonsà, una mitjana de 50 cm (fig. 12).

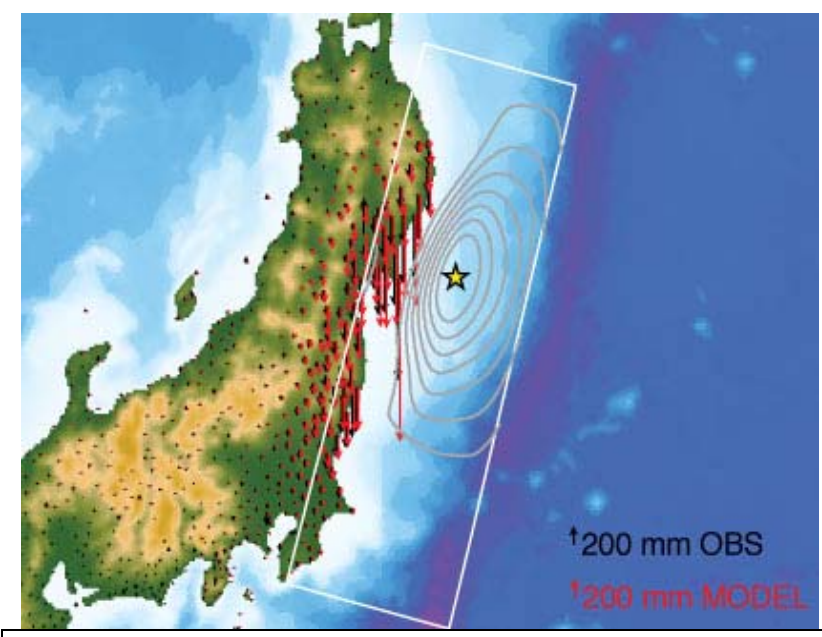

Figura 12. Moviments verticals mesurats amb GPS (negre) i predits pels models (vermell). font

Tot plegat va arribar a produir importants acceleracions del sòl (fig. 13), que van posar a prova l'estabilitat de les construccions. És notable que en un punt de la prefectura de Miyagi s'obtingués una mesura de l'acceleració de 2,7 g, un valor extremadament elevat (taula 1). En aquell punt qualsevol objecte unit al sòl va rebre una força que s'acostava al triple del seu pes. Això sol dóna una idea de les enormes forces que han de poder suportar les construccions antisísmiques.

\section{Com es va produir la ruptura?}

El terratrèmol principal es va iniciar en un punt interior de la terra -el focus o hipocentre- a 24,4 $\mathrm{km}$ de profunditat. Es tracta, per tant, d'un terratrèmol més aviat superficial. La ruptura entre les dues plaques començà a propagar-se cap al nord i cap al sud (concretament en direcció $109^{\circ}$ respecte del nord). En total es considera que la superfície de ruptura va tenir una llargada d'aproximadament 300 km i 150 d'amplada, arribant fins als $57 \mathrm{~km}$ de fondària. Mesures posteriors van mostrar que alguns punts s'havien arribat a desplaçar 40 metres. Les rèpliques, i per tant les ruptures posteriors, van implicar una extensió força més gran. Es tractava, per tant, d'una ruptura enorme que -amb la sacsejada

\begin{tabular}{|c|c|l|}
\hline $\begin{array}{c}\text { acceleració } \\
\text { (unitats } \mathrm{g})\end{array}$ & $\begin{array}{c}\text { acceleració } \\
\left(\mathrm{m} / \mathrm{s}^{2}\right)\end{array}$ & resultats observables \\
\hline 0,001 & 0,01 & perceptible per les persones \\
\hline 0,02 & 0,2 & $\begin{array}{l}\text { les persones perden la } \\
\text { verticalitat }\end{array}$ \\
\hline 0,5 & 5 & $\begin{array}{l}\text { els edificis ben dissenyats po- } \\
\text { den sobreviure si el terratrèmol } \\
\text { és de curta durada }\end{array}$ \\
\hline
\end{tabular}

Taula 1. Exemples dels efectes d'alguns valors de les acceleracions.

L'acceleració del moviment del sòl es mesura mitjançant aparells (acceleròmetres). L'acceleració 
màxima del sòl durant un terratrèmol (PGA: peak ground motion acceleration) dóna una mesura de la intensitat de la sacsejada en un punt (intensitat instrumental) que proporciona resultats equiparables a l'escala de Mercalli, que es basa en els danys observables.

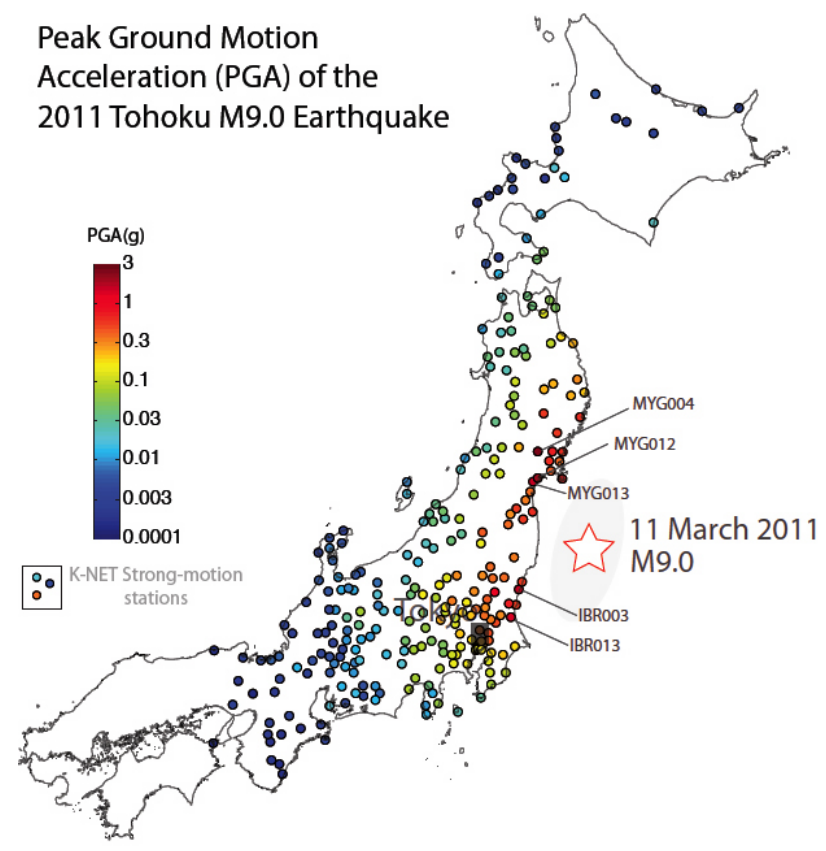

Figura 13. Acceleració màxima del terra durant el sisme expressada en unitats g (l'acceleració de la gravetat). font

\section{Per què aquests moviments?}

L'esforç en els límits entre les dues plaques les havia anat deformant. La placa pacífica, al fregar contra la vora de la placa euroasiàtica, l'havia anat comprimint cap a l'oest obligant-la a corbar-se una mica cap amunt (fig. 14a,b). Al produir-se la ruptura, el contacte entre ambdues plaques va poder alliberar aquest esforç i relaxar-se. Així, la vora de la placa euroasiàtica, en contacte amb la placa oceànica, es mogué aproximadament cap a l'est mentre la seva superfície que havia resultat corbada descendia recuperant en part la seva forma original. Això explica el moviment del sòl de l'illa cap a l'est i el seu enfonsament, més gran com més a prop de l'epicentre.

\section{Quina és la relació amb el tsunami?}

Aquests moviments de les vores de les plaques alteren, per tant, la posició del fons marí. Al damunt de la fossa, omplerta parcialment de forma sobtada, s'hi acumula un excés d'aigua, empès enlaire pel moviment del límit de placa (fig. 14c). Per altra banda, més cap a l'oest la relaxació de la seva curvatura enfonsa el fons marí produint-s'hi per tant un enfonsament relatiu de la superfície del mar. Al coincidir una depressió a la superfície de l'aigua propera a la costa, simultàniament amb una pujada més lluny de terra (fig. 15), el reequilibri de la superfície oceànica generava un moviment d'aigua cap a mar endins, però també un altre de més poderós cap a terra, a causa d'un desnivell més gran. Això va ser el que va accelerar i llançar tones i tones d'aigua oceànica contra el terra, produint el tsunami tan destructor que tots hem pogut veure.

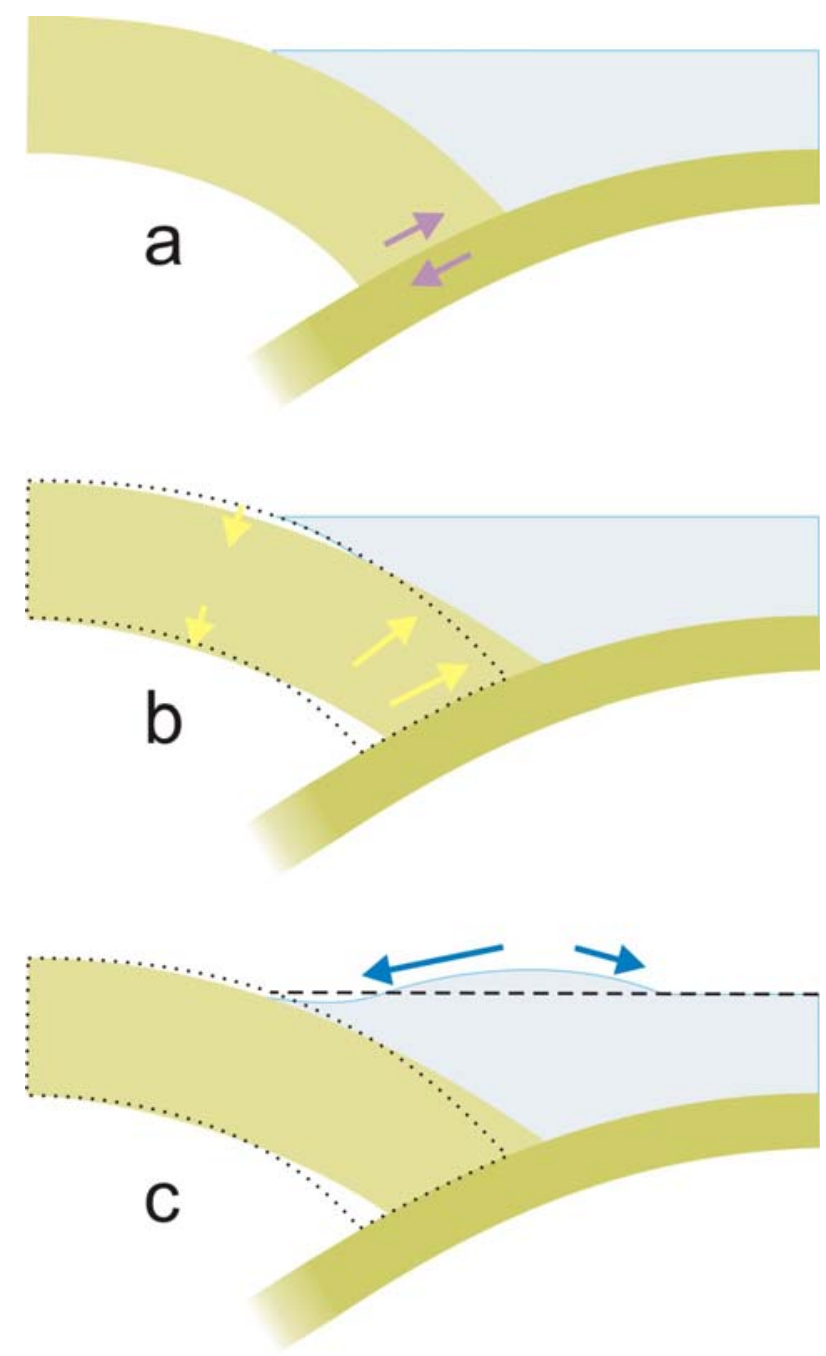

Figura 14. a) Esforç acumulat entre les dues plaques (fletxes liles). b) Alliberament de l'esforç durant el sisme i moviment (fletxes grogues) del límit de la placa euroasiàtica (en puntejat, la situació inicial). c) Deformació inicial de la superfície del mar i moviment del tsunami (fletxes blaves). 


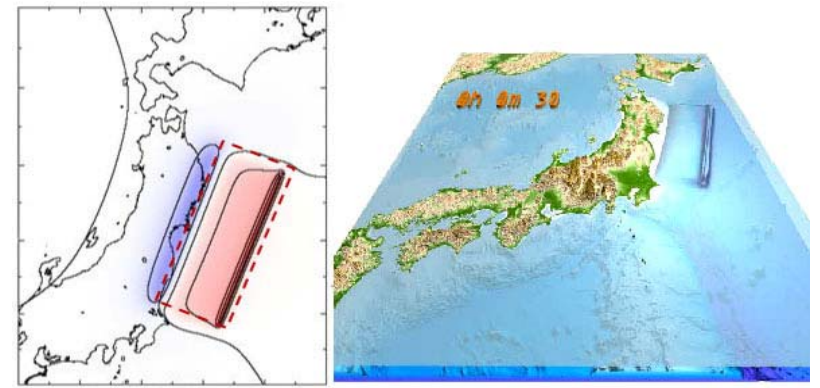

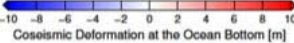

Figura 15. Mapa aproximat de l'elevació (en rosa) i l'enfonsament (blau) del fons marí (esquerra). Inici d'una simulació del tsunami de Sohoku feta pel Prof. Takashi Furumura. font

\section{Es pogué avisar la població sobre el tsunami?}

Si tenim en compte que un tsunami viatja per l'oceà a una velocitat d'uns $800 \mathrm{~km} / \mathrm{h}$, els primers llocs de la costa, com Sendai, van tenir menys de 10 minuts per preparar-se per la possible arribada d'un (figs. 16, 17 i 18).

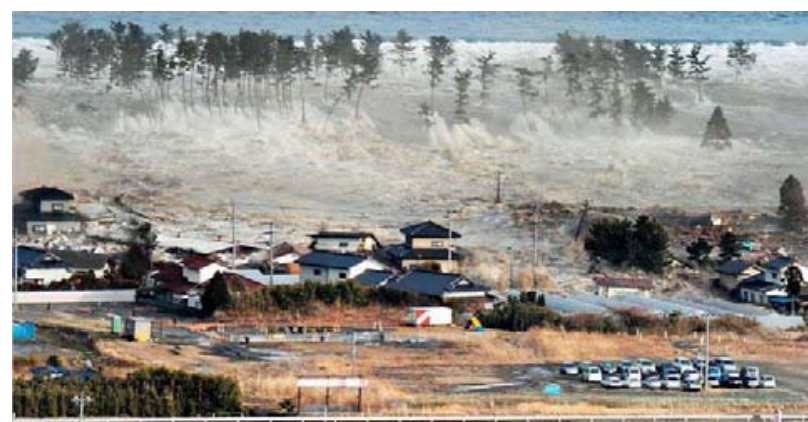

Figura 16. El tsunami avança destruint cases a la prefectura de Miyagi (AP). font

Tot i que sembla que les alarmes van funcionar possiblement es tractava d'un temps massa just perquè tothom pogués arribar a un lloc segur. De fet, els serveis de seguretat i alarma japonesos preveuen (fig. 19) un temps de només tres minuts per detectar els sisme, valorar-ne el risc i emetre, si és el cas, una alerta per tsunami.

El sistema d'alarma es basa també, a més a més dels registres sísmics, en un complex sistema de detecció de tsunamis actualment instal.lat al Pacífic i altres àrees. Consisteix en una sèrie d'estacions (fig. 20) repartides pel mar en punts relativament propers a les costes.

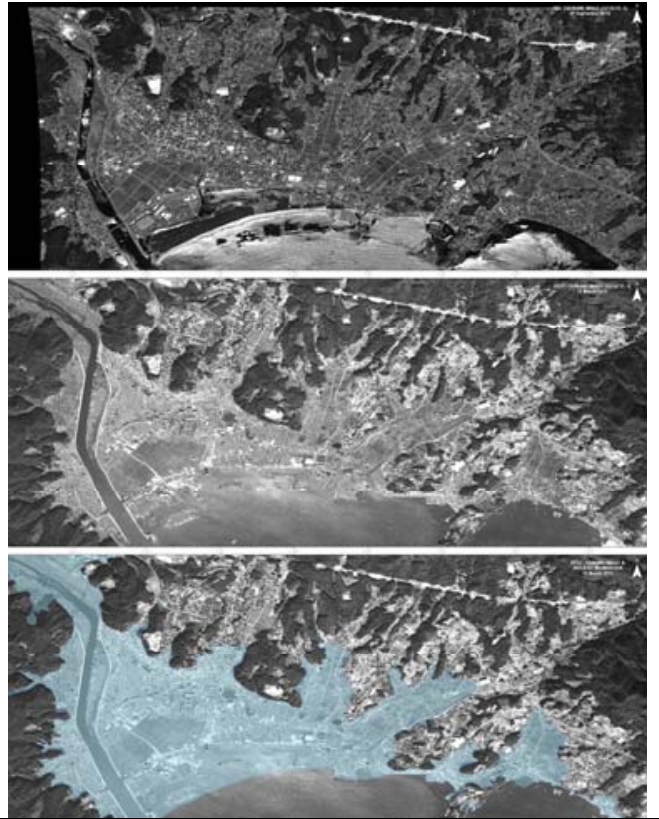

Figura 17. Comparació del mateix lloc en dates diferents: a dalt, Rikuzentakata el 29 de setembre del 2010; i al mig, el 13 de març del 2011; a sota, el color blau indica la zona que resultà devastada. font

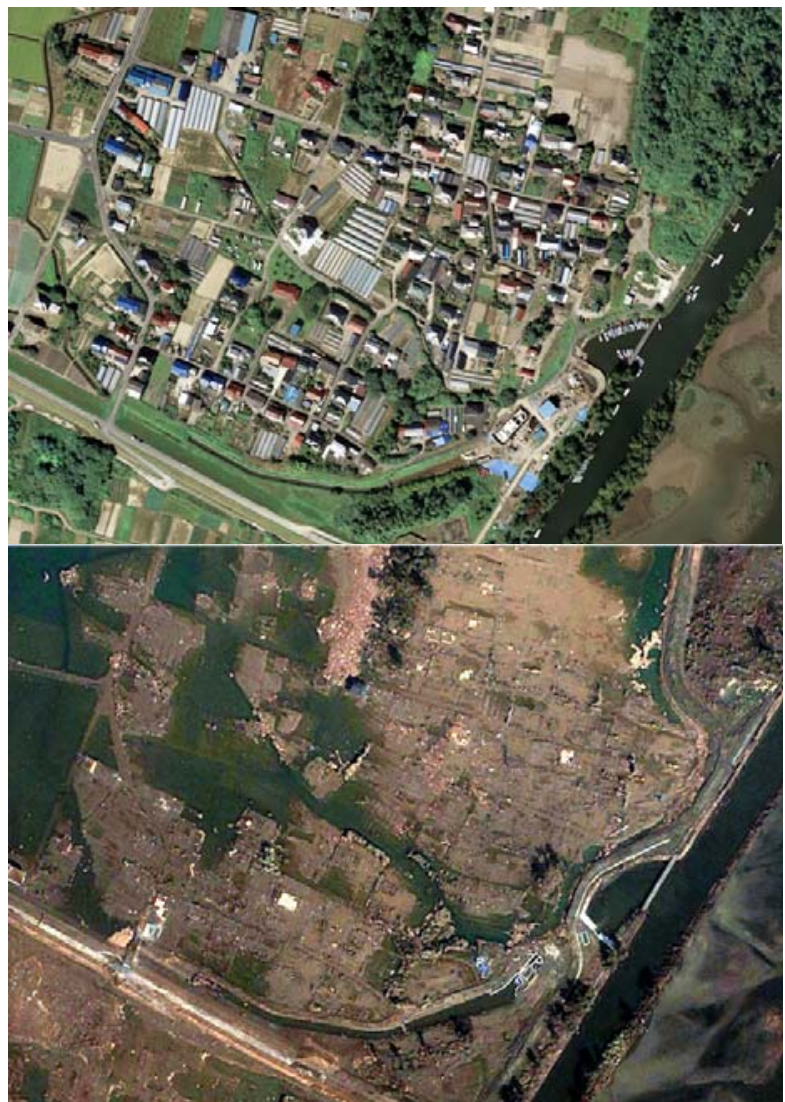

Figura 18. Comparació d'imatges de satèl-lit de Fujitsuka, a Sendai, abans i després del tsunami. font 


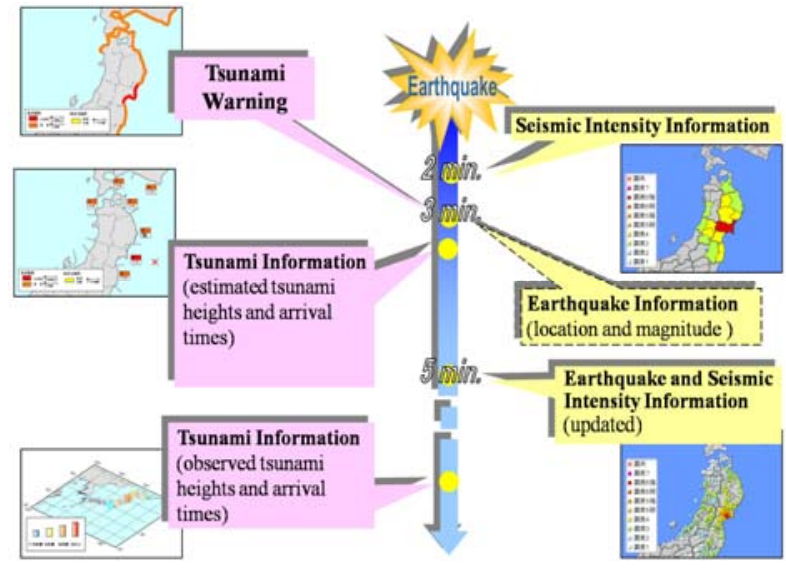

Figura 19. Seqüència de temps per a l'emissió d'informacions sobre tsunamis i sismes. font

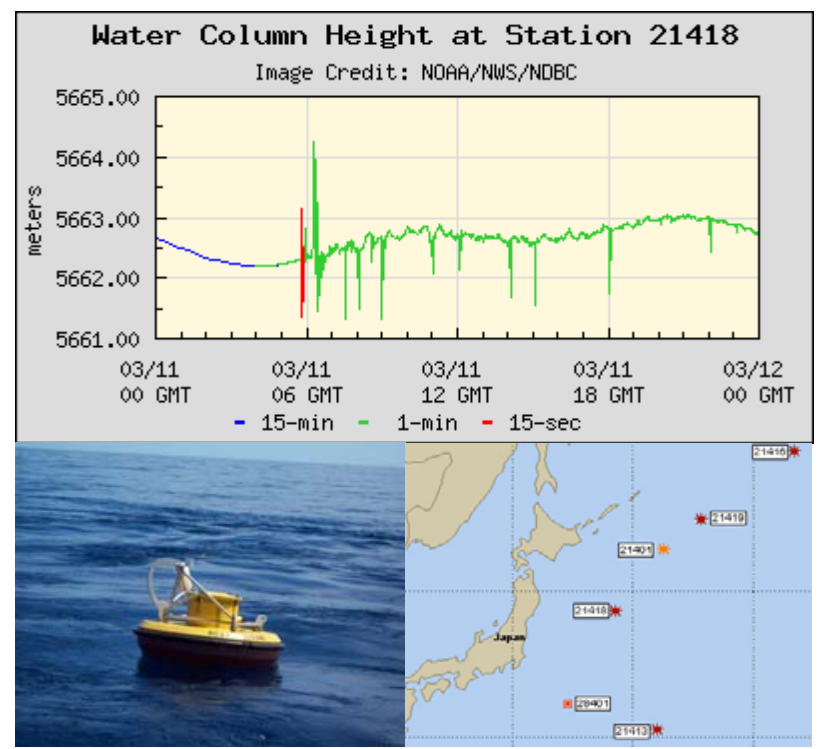

Figura 20. Detecció de l'arribada del tsunami de l'onze de març a l'estació 21418 (a la foto, boia d'una estació semblant) situada a 450 milles nàutiques al nord-est de Toquio (al mapa). font

Cada estació del sistema DART II (fig. 21) consta bàsicament d'un enregistrador de la pressió fixat en el fons del mar que periòdicament (normalment cada 15 minuts) realitza mesures i envia les seves lectures mitjançant ones acústiques a una boia flotant a la superfície, que s'encarrega d'enviar-les al centre de control via satèl.lit.

Però quan detecta una alteració en el ritme previst de pressions (el ritme de les marees), comença a realitzar mesures més sovintejades (fig. 20): cada minut o cada 15 segons. Aquestes dades, afegides a programes de modelització, fan possible preveure les característiques de la seva propagació (fig. 22) ajudant a prevenir riscos.

\section{Algunes curiositats per acabar}

La separació entre les ones individuals en imatges com la de la fig. 22 és força real ja que la seva longitud d'ona a mar obert és de centenars de quilòmetres. Això les distingeix de les ones marines habituals. Però... què és el que fa enormement més destructives?

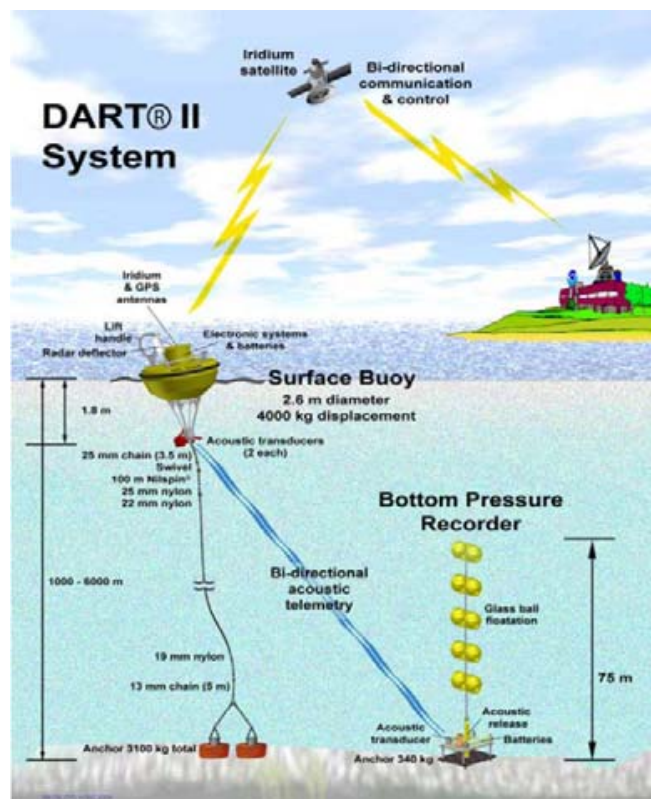

Figura 21. Diagrama general del funcionament del sistema de detecció de tsunamis DART II. font

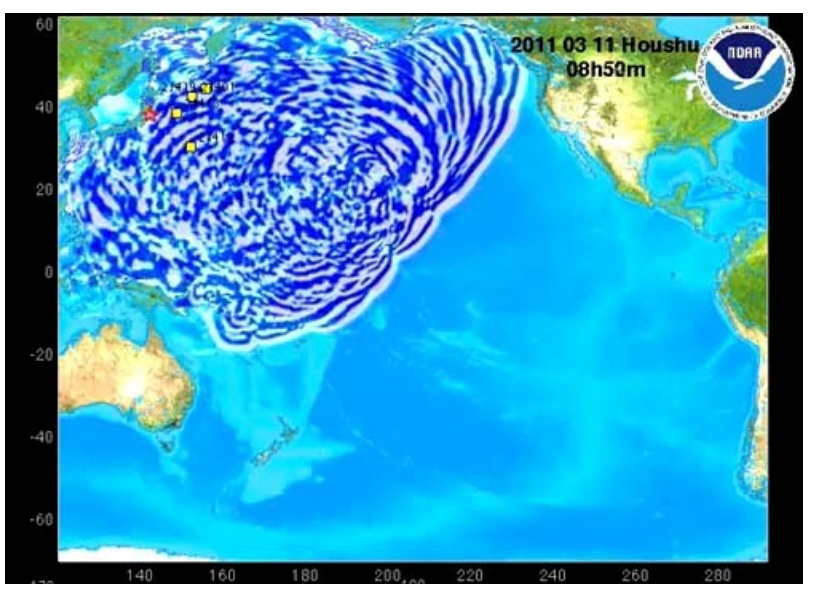

Figura 22. Modelització del tsunami de Sohoku feta per la NOAA. Les ones triguen unes 20 hores a arribar a l'Atlàntic. font

La diferència clau és que el vent posa en moviment les primeres capes de l'aigua i prou, mentre que la resta queda pràcticament immòbil (fig. 23a). En canvi, en un tsunami (fig. 23b) és pràcticament 
tota la columna d'aigua la que es mou, transportant així molta més quantitat d'energia.

Com a conseqüència d'un terratrèmol, un dels efectes que pot aparèixer és l'anomenada liqüefacció: l'aparició d'aigua provinent del subsòl (fig. 24). Això és degut a la mateixa causa que fa que quan espremem una esponja molla en surti aigua: la compressió de la capa freàtica pot obligar l'aigua a sortir del subsòl pel allà on li sigui possible.

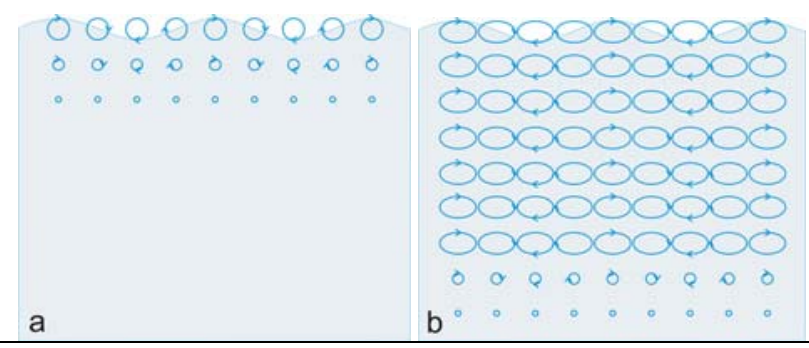

Figura 23. Comparació entre el moviment de l'aigua en les ones marines superficials (a) i en un tsunami (b). La longitud d'ona és de l'ordre de metres en el primer cas i de centenars de quilòmetres en el segon.

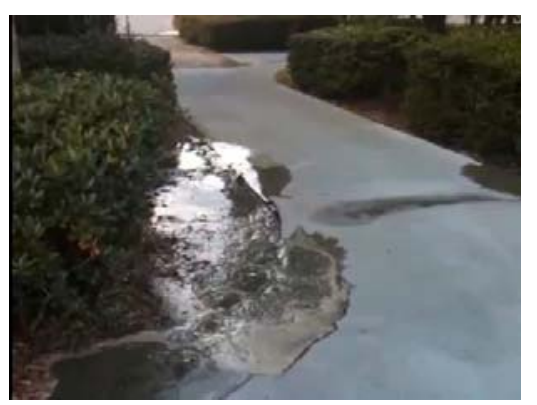

Figura 24. Liqüefacció al parc central de Tòquio. font
Com que el moviment sísmic ha suposat, en conjunt, l'enfonsament d'uns materials que s'havien anat elevant, la distribució de massa de la Terra ha quedat alterada. La conservació del moment cinètic exigeix que al disminuir el radi de gir d'aquests materials, la velocitat de gir de la Terra hagi d'augmentar. És el que ha provocat una disminució en la llargada del dia de 1,8 $\mu \mathrm{s}$.

Finalment, és interessant constatar que pocs minuts després del terratrèmol del Japó els aparells van enregistrar un sobtat increment en l'oscillació del nombre d'electrons a la ionosfera sobre de l'illa Honshu (fig. 25). Es tracta d'un fenomen igualment observat en grans terratrèmols i que té relació amb la propagació de les ones infrasòniques per la superfície terrestre, que també fa vibrar les diverses capes de l'atmosfera, sobretot la ionosfera, que és la de menor densitat.

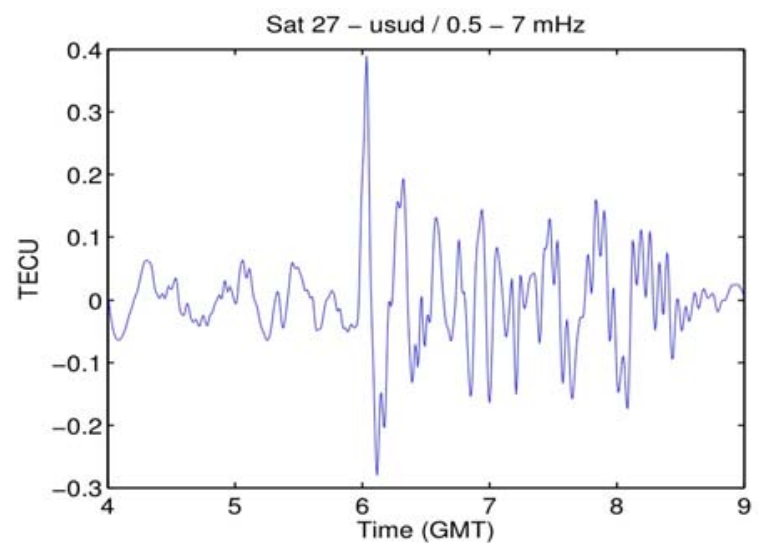

Figura 25. Variació del nombre d'electrons respecte del valor normal a la ionosfera, a $300 \mathrm{~km}$ d'alçada, sobre l'illa Honshu. A partir de les 6, minuts després del terratrèmol, s'observa una intensa oscil.lació en aquesta quantitat. font 